\title{
Comparative researches on two direct transmethylation without prior extraction methods for fatty acids analysis in vegetal matrix with low fat content
}

\author{
Monica Harmanescu
}

\begin{abstract}
Background: The aim of our work was to compare two methods, both based on direct transmethylation with different reagents, $\mathrm{BF}_{3} / \mathrm{MeOH}$ (boron trifluoride in methanol) or $\mathrm{HCl} / \mathrm{MeOH}$ (hydrochloride acid in methanol), in acid catalysis, without prior extraction, to find the fast, non-expensive but enough precise method for 9 principal fatty acids (lauric, myristic, palmitic, stearic, oleic, linoleic, linolenic, arahidic and behenic acids) analysis in vegetal matrix with low fat content (forage from grassland), for nutrition and agrochemical studies.

Results: Comparatively, between the average values obtained for all analysed fatty acids by the two methods based on direct transmethylation without prior extraction no significantly difference was identified ( $p>0.05)$. The results of fatty acids for the same forage sample were more closely to their average value, being more homogenous for $\mathrm{BF}_{3} / \mathrm{MeOH}$ than $\mathrm{HCl} / \mathrm{MeOH}$, because of the better accuracy and repeatability of this method. Method that uses $\mathrm{BF}_{3} / \mathrm{MeOH}$ reagent produces small amounts of interfering compounds than the method using $\mathrm{HCl} / \mathrm{MeOH}$ reagent, results reflected by the better statistical parameters.

Conclusion: The fast and non-expensive $\mathrm{BF}_{3}$ /methanol method was applied with good accuracy and sensitivity for the determination of free or combined fatty acids (saturated and unsaturated) in forage matrix with low fat content from grassland. Also, the final extract obtained by this method, poorer in interfering compounds, is safer to protect the injector and column from contamination with heavy or non-volatile compounds formed by transmethylation reactions.
\end{abstract}

\section{Background}

Lipids play diverse and important roles in nutrition and health and many lipids are absolutely essential for life. For instance, humans have dietary requirements for certain essential fatty acids (e.g., linoleic acid and $\alpha$-linolenic acid), because they cannot be synthesized from simple precursors in our diet [1]. For humans lipids source can be the foods with animal origin and oleaginous seeds but for herbivores the lipids source is only natural forage or concentrates. Many studies were made about the influence of nutrition types on lipids composition of foods from poultry (meat and eggs), pork (meat)

Correspondence: monicaharmanescu@yahoo.com

Banat's University of Agricultural Sciences and Veterinary Medicine from Timisoara, Faculty of Agriculture, RO 300645, Romania and herbivores (meat and milk) [2-6]. It is widely accepted that ruminants grazing or feeding with natural forage are beneficial to produce meat and dairy foods with healthier lipid composition than those fed with concentrates $[7,8]$. Hence, the increased interest to obtain vegetal matrix from grasslands with higher production, both qualitative and quantitative.

Conventional techniques for the extraction of fatty acids (FAs) in animal feed require Soxhlet extraction (with large volume of organic solvent), purification, hydrolysis, and transmethylation procedures that are both lengthy and cumbersome. Attempts to bypass extraction and purification steps have met with varying degrees of success. Many reports propose different techniques that exclude most of the preparative steps and consist of a one-step procedure. In this procedure FAs 
are simultaneously extracted and methylated by using a basic or acid catalyst. Fatty acids composition of plasma, feces, bile and liver was analysed by 1 hour direct transmethylation procedure carried out in methanol-benzene 4:1 with acetyl chloride [9]. The method was applicable for analysis of both simple (triglycerides) and complex lipids (cholesteryl-esters, phospholipids; and sphingomyelin) $[9,10]$. In application of nutritional and epidemiological studies, where the knowledge of fatty acids status is necessary, was successfully developed a rapid micromethod by direct transmethylation $(3 \mathrm{~N} \mathrm{HCl} / \mathrm{MeOH})$ in a drop of human blood [11]. Different vegetal materials like peanuts [12], herbage [13], yeast [14], Artemia shrimp [15] were successfully investigated for fatty acids contents by direct transmethylation in one-step procedure, using as direct transmethyltion reagents: $\mathrm{BF}_{3} /$ $\mathrm{MeOH}, 5 \% \mathrm{HCl}-\mathrm{MeOH} /$ Toluene, $2 \% \mathrm{H}_{2} \mathrm{SO}_{4} / \mathrm{MeOH}$ and $\mathrm{HCl}-\mathrm{MeOH} /$ Benzene. They lead to more complete recoveries of all classes of lipids which, during the transmethylation procedure, are free from biological specimens.

Our goal was to identify a fast and enough precise method to determine the fatty acids in forage from permanent grassland in order to monitor the changes in their status by applying different types of fertilization. Data provided by the literature recommended direct transmethylation of feed samples using acid catalysis based on $\mathrm{HCl} / \mathrm{MeOH}$ or $\mathrm{BF}_{3} / \mathrm{MeOH}$ reagents $[13,16]$. In a critical study done by Weston et al. [16] shows that both methods have similar qualities but encourage all to use analytical reagent $\mathrm{HCl} / \mathrm{MeOH}$ mainly due to its lower cost. But due to the large amounts of by-product (esters of organic acids present in plants, compounds of decomposition of sugars), Alves et al. [13,17] introduce their separation by SPE (solid phase extraction). Analytical results obtained by using SPE separation are superior but introduce a further step in the analytical process, which makes it less productive and more expensive. In this context we have reviewed the two methods of direct transmethylation without prior extraction to see which one can exclude SPE separation, without sacrifice the quality of the results.

\section{Results and discussion}

\section{Quantification of FAs using $\mathrm{BF}_{3} / \mathrm{MeOH}$ vs. $\mathrm{HCl} / \mathrm{MeOH}$ method}

Table 1 presents principal FAs composition of the forage from the 10 trials, with different types of fertilization, processed using $\mathrm{BF}_{3} / \mathrm{MeOH}$ and $\mathrm{HCl} / \mathrm{MeOH}$ methods. Statistical treatment was made with ANOVA: two factors with replication. Fixed factor A were the two methods $\left(\mathrm{BF}_{3} / \mathrm{MeOH}\right.$ and $\left.\mathrm{HCl} / \mathrm{MeOH}\right)$ and factor B: fatty acids compositions.

In forage from trials with organic fertilizer (D2-D4) the sum of total fatty acids increased considerably comparatively with the control (D1), from 4549.4 to 9114.4 mg/kg DM. This increase was observed particularly in the case of unsaturated fatty acids. The most important FAs identified in forage samples were the linoleic acid (18:2n6), ranged from 2909 - $3252 \mathrm{mg} / \mathrm{kg}$ DM for trial with high dose of organic fertilizer (D4). For the same trial, palmitic acid (16:0) ranged from 2414 to $2623 \mathrm{mg} / \mathrm{kg} \mathrm{DM}$, linolenic acid (18:3n6) ranged from 1808 to $1988 \mathrm{mg} / \mathrm{kg} \mathrm{DM}$ and oleic acid (18:1n9) from 852 to $971 \mathrm{mg} / \mathrm{kg}$ DM. Lauric (12:0), myristic (14:0), stearic (18:0), arahidic (20:0) and behenic (22:0) fatty acids are the minor components of the forage's lipids, ranged from 15 to $210 \mathrm{mg} / \mathrm{kg} \mathrm{DM}$ [18]. For the forage from trials with only mineral fertilization (D8D10) a significant decrease of total fatty acids contents was observed comparatively with the control (D1), from 4549.4 to $3245.0 \mathrm{mg} / \mathrm{kg} \mathrm{DM}$. Also in these cases the most obvious decrease was observed for unsaturated fatty acids. For forage from trials with mix fertilization (D5-D7) the decrease is less pronounced comparatively with the control, from 4549.4 to $4053.9 \mathrm{mg} / \mathrm{kg} \mathrm{DM}$. From these data we conclude that the type of fertilization has an important impact on fatty acids composition of forage matrix from grassland.

Even significant differences $(\mathrm{p}<0.001)$ were identified between FAs composition of forage from the same permanent grassland, depending by the type of fertilization, between the two tested methods no significant variations were identified for all analysed fatty acids ( $p>0.05$ ).

Although no significant differences between the contents in FAs were determined by the two methods, the statistical parameters standard deviation (SDV) and relative standard deviation (RSDV) were higher for $\mathrm{HCl}$ / $\mathrm{MeOH}$ method. This can be explained by the existence of strong interferences in the case of $\mathrm{HCl} / \mathrm{MeOH}$ method. The strong acid medium and the high temperature of this method may cause the appearance of a great quantity of interfering compounds, and many of them can interfere in the GC analysis [13,17]. The more accentuated presence of interfering compounds in final extract of $\mathrm{HCl} / \mathrm{MeOH}$ method can be observed also visually. The colour of hexane extracts of $\mathrm{HCl} / \mathrm{MeOH}$ method are more dark (green-brown) than the hexane extracts obtained by $\mathrm{BF}_{3}$ method (see Additional file 1). Alves et al $[13,18]$ improved this direct transmethylation method $(\mathrm{HCl} / \mathrm{MeOH})$ using SPE step for removing the major interfering compounds. They also identified the most important interfering compounds by this GCMS analysis. These compounds are formed mainly from phytadienes (the presence of fragment ions at $\mathrm{m} / \mathrm{z} 81$, 95 and 123 in mass spectrum of the chromatographic peak), methyl levulinate and different methyl esters of non-volatile organic acids (oxalic, succinic, malonic and quinic acids) [13,17]. Phytadienes compounds may be 
Table 1 Fatty acids composition of the forage from the 10 trials with different fertilization, using $\mathrm{BF}_{3} / \mathrm{MeOH}$ and $\mathrm{HCl} /$ MeOH methods (average contents of 3 different samples for each trial; significance: $\mathbf{n s}=\mathbf{p}>0.05, * * *=p<0.001$ )

\begin{tabular}{|c|c|c|c|c|c|c|c|c|c|c|c|c|}
\hline \multirow[b]{2}{*}{ FA/Fertilized trials } & \multicolumn{10}{|c|}{ Fatty acids, $\mathrm{mg} \mathrm{kg}^{-1}$} & \multicolumn{2}{|c|}{ Significance } \\
\hline & $\begin{array}{l}\text { Lauric } \\
(12: 0)\end{array}$ & $\begin{array}{c}\text { Myristic } \\
(14: 0)\end{array}$ & $\begin{array}{c}\text { Palmitic } \\
(16: 0)\end{array}$ & $\begin{array}{c}\text { Stearic } \\
(18: 0)\end{array}$ & $\begin{array}{c}\text { Oleic } \\
(18: 1 n 9)\end{array}$ & $\begin{array}{l}\text { Linoleic } \\
(18: 2 n 6)\end{array}$ & $\begin{array}{c}\text { Linolenic } \\
(18: 3 n 3)\end{array}$ & $\begin{array}{c}\text { Arahidic } \\
(20: 0)\end{array}$ & $\begin{array}{c}\text { Behenic } \\
(22: 0)\end{array}$ & FAs Sum & $\begin{array}{c}\mathrm{A} \\
\text { (methods) }\end{array}$ & $\begin{array}{c}B \\
\text { (FAs) }\end{array}$ \\
\hline \multicolumn{13}{|c|}{$\mathrm{BF}_{3} / \mathrm{MeOH}$ method } \\
\hline D1 & 33.4 & 73.7 & 1644.4 & 237.1 & 465.8 & 1167.9 & 665.7 & 132.2 & 129.2 & 4549.4 & ns & $* * *$ \\
\hline D2 & 19.1 & 55.2 & 1876.3 & 239.9 & 564.7 & 1712.3 & 1605.9 & 127.0 & 103.9 & 6304.3 & ns & $* * *$ \\
\hline D3 & 23.3 & 79.0 & 2257.6 & 424.1 & 736.8 & 2681.0 & 1546.9 & 169.4 & 154.6 & 8072.7 & ns & $* * *$ \\
\hline D4 & 18.6 & 65.0 & 2413.7 & 509.8 & 851.8 & 2909.5 & 1988.1 & 207.5 & 150.5 & 9114.4 & ns & $* * *$ \\
\hline D5 & 15.6 & 47.8 & 1729.9 & 295.8 & 565.0 & 1929.3 & 757.0 & 202.1 & 122.2 & 5664.7 & ns & $* * *$ \\
\hline D6 & 15.3 & 51.4 & 1764.1 & 282.9 & 513.5 & 1471.4 & 749.4 & 125.1 & 76.3 & 5049.5 & ns & $* * *$ \\
\hline D7 & 24.0 & 59.2 & 1474.4 & 200.3 & 423.2 & 1027.3 & 615.4 & 124.4 & 105.8 & 4053.9 & ns & $* * *$ \\
\hline D8 & 18.4 & 55.9 & 1535.4 & 189.4 & 441.7 & 1069.6 & 608.2 & 106.8 & 96.0 & 4121.4 & ns & $* * *$ \\
\hline D9 & 20.6 & 52.8 & 1531.5 & 179.0 & 352.2 & 721.6 & 509.7 & 93.2 & 77.5 & 3538.1 & ns & $* * *$ \\
\hline D10 & 18.4 & 46.2 & 1378.7 & 156.4 & 298.4 & 673.4 & 475.0 & 104.2 & 94.2 & 3245.0 & ns & $* * *$ \\
\hline Average SDV & 1.9 & 3.2 & 61.4 & 14.7 & 15.0 & 10.7 & 7.9 & 6.6 & 13.3 & 131.4 & & \\
\hline Average RSDV \% & 25.5 & 9.9 & 4.3 & 7.8 & 6.2 & 1.9 & 1.4 & 7.4 & 12.2 & 4.0 & & \\
\hline \multicolumn{13}{|c|}{$\mathrm{HCl} / \mathrm{MeOH}$ method } \\
\hline D1 & 14.2 & 43.1 & 1642.0 & 236.7 & 577.5 & 1349.6 & 523.8 & 142.0 & 70.5 & 4599.4 & ns & $* * *$ \\
\hline D2 & 8.8 & 17.6 & 1805.7 & 232.3 & 620.9 & 1673.7 & 1310.5 & 115.1 & 77.1 & 5861.6 & ns & $* * *$ \\
\hline D3 & 2.8 & 13.5 & 2208.5 & 518.3 & 974.6 & 2781.7 & 1223.9 & 131.0 & 156.3 & 8010.7 & ns & $* * *$ \\
\hline D4 & 4.8 & 44.2 & 2622.6 & 542.2 & 970.9 & 3252.0 & 1808.1 & 230.5 & 238.9 & 9714.2 & ns & $* * *$ \\
\hline D5 & 9.6 & 12.4 & 1876.8 & 341.9 & 782.5 & 2175.4 & 728.3 & 252.8 & 160.1 & 6339.9 & ns & $* * *$ \\
\hline D6 & 4.1 & 26.9 & 1731.4 & 271.3 & 534.3 & 1388.7 & 612.0 & 136.7 & 118.1 & 4823.6 & ns & $* * *$ \\
\hline D7 & 5.4 & 24.1 & 1449.8 & 178.2 & 438.1 & 1146.9 & 489.1 & 108.5 & 105.9 & 3946.0 & ns & $* * *$ \\
\hline D8 & 12.3 & 42.5 & 1674.6 & 223.7 & 499.4 & 1241.3 & 536.2 & 124.6 & 135.9 & 4490.6 & ns & $* * *$ \\
\hline D9 & 15.1 & 38.8 & 1401.4 & 188.6 & 328.8 & 721.2 & 423.6 & 67.9 & 108.9 & 3294.3 & ns & $* * *$ \\
\hline D10 & 8.2 & 49.3 & 1467.6 & 186.9 & 444.7 & 805.2 & 402.6 & 100.7 & 119.1 & 3584.4 & ns & $* * *$ \\
\hline Average SDV & 4.9 & 4.2 & 218.1 & 72.2 & 189.1 & 115.9 & 68.6 & 6.7 & 13.5 & 669.4 & & \\
\hline Average RSDV\% & 130.6 & 18.0 & 13.2 & 29.5 & 54.3 & 17.9 & 11.6 & 7.7 & 13.9 & 18.1 & & \\
\hline
\end{tabular}

derived from phytol, a degradation product of chlorophyll phytyl chain [19], methyl levulinate and other methyl esters are formed by hydrolysis of fructose, respectively other sugars present in herbages, in acidcatalysed reactions $[20,21]$. To evaluate the losses during the two tested methods, recovering test was employed by spiking 6 HRMs (homemade reference materials) samples with the same concentration $(1 \mathrm{mg} / \mathrm{mL})$ of margaric fatty acids (C17:0) standard. GCMS analysis of extracts obtained from these HRMs, by the two methods, highlights the lower contents of such interfering compounds in the extracts obtained by $\mathrm{BF}_{3} / \mathrm{MeOH}$ method (Figures 1 and 2). Partial overlapping chromatograms of several organic acids and phytadienes are presented in Figure 2.

All interfering compounds were identified by analysis of GCMS chromatograms using equipment's MS library (NIST) and literature information about mass spectrum
[13]. Quantitative analysis of interfering compounds were made using margaric (C17:0) fatty acid as internal standard.

\section{Recovering results}

Table 2 shows the recovering results of the 6 HRMs, 3 samples (HRMs 1-3) assessed by margaric fatty acid content by $\mathrm{BF}_{3} / \mathrm{MeOH}$ method and 3 samples (HRMs 4-6) by $\mathrm{HCl} / \mathrm{MeOH}$ method.

The average recovery for HRMs spiked at concentration level of $1.0 \mathrm{mg} / \mathrm{mL}$ was $95.75 \%$ for $\mathrm{BF}_{3} / \mathrm{MeOH}$ method and $87.53 \%$ for $\mathrm{HCl} / \mathrm{MeOH}$ method. SDV and RSDV for two methods were $0.028,2.98 \%$, and respectively $0.059,6.80 \%$. The recovery percentage and statistical parameters for method $\mathrm{BF}_{3} / \mathrm{MeOH}$ were better than the same parameters for $\mathrm{HCl} / \mathrm{MeOH}$ method. These differences can be associated with interfering substances that are higher in case of $\mathrm{HCl} / \mathrm{MeOH}$ method. 


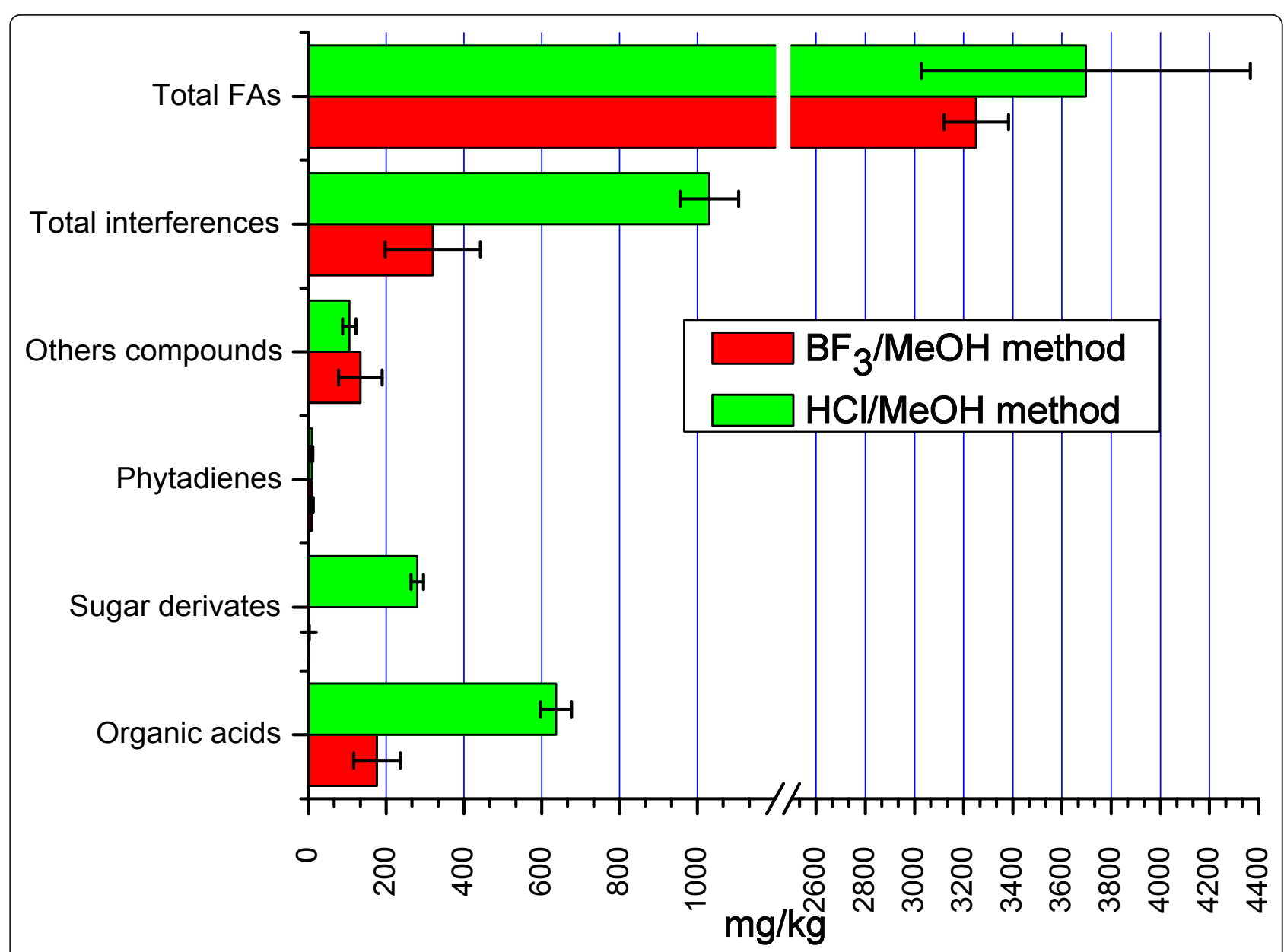

Figure 1 Comparative data for total FAs and interfering compounds, obtained by the two methods at HRMs $(n=3)$.

The repeatability of the two methods was determined by the coefficient of variation (CV \%) of three consecutive analyses. This variation was around $0.1 \%$ for $\mathrm{BF}_{3} /$ $\mathrm{MeOH}$ method and around $0.4 \%$ for $\mathrm{HCl} / \mathrm{MeOH}$ method, indicating that both assayed methods provide a good accuracy and repeatability range.

\section{Experimental}

\section{Experimental site}

The experimental site (permanent grassland) was situated near Gradinari village $\left(45.151{ }^{\circ} \mathrm{N} / 21.538^{\circ} \mathrm{E}\right)$ altitude $200 \mathrm{~m}$, a hill area in Banat County, Romania. The agrochemical experiment begins in 2003, when permanent grassland was divided in ten trials with five replications for each of them: D1-unfertilized trial; D2, D3, D4 - fermented sheep manure (20 to $60 \mathrm{t} / \mathrm{ha}$ ), D5, D6, D7 organic and mineral fertilizers (20 t/ha fermented sheep manure and different combination of $50 \mathrm{~kg} / \mathrm{ha}$ of $\mathrm{P}_{2} \mathrm{O}_{5}$, $\mathrm{K}_{2} \mathrm{O}, \mathrm{N}$ ); D8, D9, D10 - only mineral fertilizers (constant doses of $50 \mathrm{~kg} / \mathrm{ha} \mathrm{P}_{2} \mathrm{O}_{5}+50 \mathrm{~kg} / \mathrm{ha} \mathrm{K}_{2} \mathrm{O}$ and different $\mathrm{N}$ doses: 100,150 , and respectively $100+100 \mathrm{~kg} / \mathrm{ha})$. The mineral fertilizers were applied yearly, while the fermented sheep manure at each two years in late winter. The trials were arranged in randomized plots, in multiple stage blocks. The soil of permanent grassland was Calcic Luvisol. The annual average temperature in this region was around $10.4^{\circ} \mathrm{C}$.

\section{Samples collection and preparation}

In plants fatty acids can be found in scarce amounts in free form, but generally they are combined in more complex molecules through ester bonds. The analysis of total fatty acids from biological materials is a complex task and precautions should be taken at all times to prevent or minimize the effects of degradation/oxidation by long time and high temperature manipulation of samples. Fresh samples of forage were collected in middle of June from permanent grassland of the BUASVM (Banat's University of Agricultural Sciences and Veterinary Medicine from Timisoara) experimental field, Gradinari village. For laboratory samples, herbages from $1 \mathrm{~m}^{2}$ were cut $5 \mathrm{~cm}$ above soil, kept in plastic bags at $4{ }^{\circ} \mathrm{C}$ and rapidly taken to the laboratory and dried at $70^{\circ} \mathrm{C}$ 


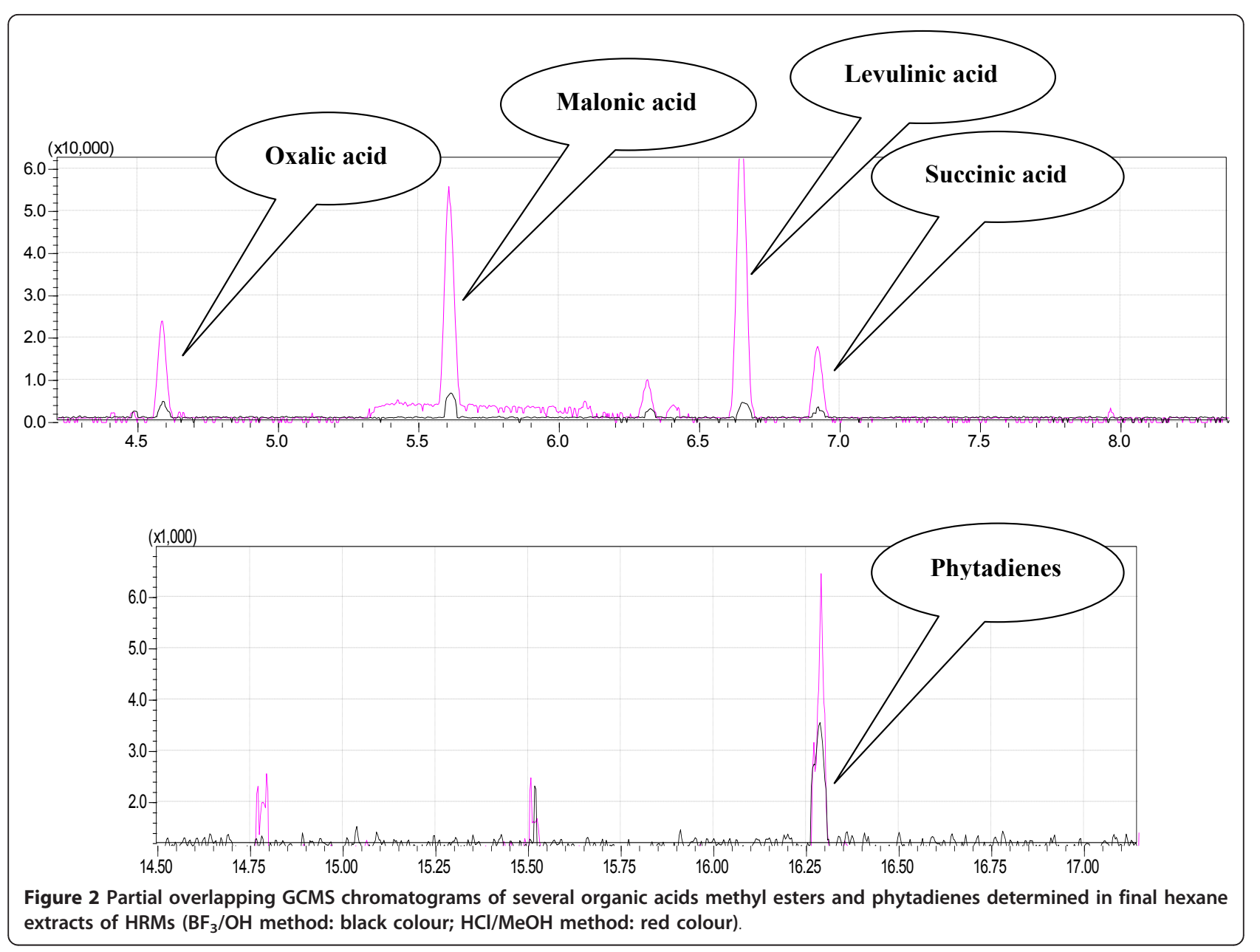

Table 2 Recovery results of margaric fatty acid standard (C17:0) added to HRMs processed with direct transmethylation by the two methods $(n=3)$

\begin{tabular}{ccc}
\hline HRMs samples & Recovery (mg) & Recovery (\%) \\
\hline \multicolumn{3}{c}{$\mathbf{B F}_{3} / \mathbf{M e O H}$ method } \\
\hline HRM1 & 0.989 & 98.94 \\
\hline HRM 2 & 0.949 & 94.88 \\
\hline HRM 3 & 0.934 & 93.42 \\
\hline Average & $\mathbf{0 . 9 6 8}$ & $\mathbf{9 5 . 7 5}$ \\
\hline SDV & 0.028 & 2.86 \\
\hline RSDV \% & & 2.98 \\
\hline CV \% & & 0.083 \\
\hline HRM 4 & \\
\hline HRM 5 & 0.809 & 80.93 \\
\hline HRM 6 & 0.924 & 92.36 \\
\hline Average & 0.893 & 89.30 \\
\hline SDV & $\mathbf{0 . 8 7 5}$ & $\mathbf{8 7 . 5 3}$ \\
\hline RSDV \% & 0.059 & 5.91 \\
\hline CV \% & 6.80 \\
\hline
\end{tabular}

for short time $(10 \mathrm{~min})$ for stopped the enzymatic activity and after that, samples were dried at $45^{\circ} \mathrm{C}$ in ventilated oven (to constant mass, around $24 \mathrm{~h}$ ), ground to pass a $0.5 \mathrm{~mm}$ screen and kept in dark and dry atmosphere at room temperature until analysis. 30 forage samples from 10 agrochemical experimental trials with different type of fertilization were analysed by the two $\mathrm{BF}_{3} / \mathrm{MeOH}$ and $\mathrm{HCl} / \mathrm{MeOH}$ methods for common 9 fatty acids (6 saturated and 3 unsaturated), predominantly found in forage [18]. The floristic matrix of forage (gravimetrically) consist in: Festuca rupicola (16 52\%), Calamagrostis epigejos (5 - 13\%), Poa pratensis (around 5\%), Alopecurus pratensis (under 2\%), Trifolium repens (7 - 38\%), Trifolium medium (under 3\%), Lathyrus pratensis (under 6\%), Medicago falcata (under $2 \%)$, Rosa canina (7 - 18\%), Filipendula vulgaris (3 9\%), Inula britanica (under 5\%), Galium verum (under $7 \%$ ) and Plantago lanceolata (under 3\%). The grasses were dominant in trials fertilized with mineral nitrogen, while the leguminous prevail in forage from trials fertilized with fermented sheep manure. 


\section{Methods \\ $\mathrm{BF}_{3} / \mathrm{MeOH}$ method}

The working method was adapted after Weston et al. [16]. $50 \mu \mathrm{L}$ of internal standard (C17:0, $20 \mathrm{mg} / \mathrm{mL})$ and $2.5 \mathrm{~mL}$ of $20 \%$ boron trifluoride-methanol reagent were added to weighed amounts of sample (0.3-0.5 grams dry matter) in a $20 \mathrm{~mL}$ centrifuge tube provided with a Teflon-lined screw cap under the nitrogen. The tube was closed, heated at $70^{\circ} \mathrm{C}$ for $30 \mathrm{~min}$ (ultrasound bad), then cooled and $1 \mathrm{~mL}$ of $10 \% \mathrm{NaCl}$ aqueous solution were added. FAMEs were extracted with $2 \mathrm{~mL}$ of hexane, and $1 \mathrm{~g}$ of both $\mathrm{Na}_{2} \mathrm{SO}_{4}$ and activated carbon were added. Finally, samples were centrifuged for $5 \mathrm{~min}$ at $2500 \mathrm{rpm}$. $1.5 \mathrm{~mL}$ of the supernatant was transferred to auto sampler vial for GCMS analysis.

\section{$\mathrm{HCl} / \mathrm{MeOH}$ method}

The working method was adapted after Alves et al. [13]: $50 \mu \mathrm{L}$ of internal standard $(\mathrm{C} 17: 0,20 \mathrm{mg} / \mathrm{mL})$ and $1 \mathrm{~mL}$ of toluene were added to $250 \mathrm{mg}$ of sample, followed by the addition of $3 \mathrm{~mL}$ of $5 \% \mathrm{HCl}$ solution in methanol (prepared by the addition of acetyl chloride to the methanol). After homogenization on vortex at slow speed, samples were maintained for $2 \mathrm{~h}$ at $70^{\circ} \mathrm{C}$ in ultrasound water bath. After that, the solution was placed in a cool place at room temperature and subsequently neutralized with $5 \mathrm{~mL}$ of $6 \% \mathrm{~K}_{2} \mathrm{CO}_{3}$. FAMEs were extracted with $2 \mathrm{~mL}$ of hexane, and $1 \mathrm{~g}$ of both $\mathrm{Na}_{2} \mathrm{SO}_{4}$ and activated carbon were added. Finally, samples were centrifuged for $5 \mathrm{~min}$ at $2500 \mathrm{rpm}$. $1.5 \mathrm{~mL}$ of the supernatant was transferred to auto sampler vial for GCMS analysis.

\section{GCMS quantification method}

The device used was GCMS QP 2010 (Shimadzu). This GCMS system equipped with a split/split less injector (set at 10:1) was used to analyse the derivatives of fatty acids. Separations were achieved using a fused silica Zebron ZB-FFAP capillary column $(60 \mathrm{~m} \times 0.25 \mathrm{~mm}$ ID, $0.25 \mu \mathrm{m}$ film thickness). Helium was used as the carrier gas at flow rates of $1.99 \mathrm{~mL} / \mathrm{min}$. Temperature of injector was held constant at $250^{\circ} \mathrm{C}$. The oven temperature was programmed as following: $140^{\circ} \mathrm{C}$ initially hold $10 \mathrm{~min}$, and then increased to $250^{\circ} \mathrm{C}$ at $7^{\circ} \mathrm{C} / \mathrm{min}$, with the final hold for $10 \mathrm{~min}$, with $35.71 \mathrm{~min}$ total time of GCMS analysis. LabSolution software was used to control the operation of GCMS, obtain the chromatograms, and perform data calculations.

MS parameters: ion source temperature: $210^{\circ} \mathrm{C}$; interface temperature: $255^{\circ} \mathrm{C}$; solvent cut time: $3 \mathrm{~min}$; ionization mode: SEI; acquisition mode: scan; event time: 0.20; scan speed: 2500; start m/z: 40; end m/z: 500 .

Quantification of FAs was made by external standard method. For the calibration assays, linear regression analysis was conducted by plotting response area vs. concentration. Three replicates were made to obtain relative standard deviations (RSD, ranged from 4 to $13 \%)$, slope and coefficient of determination $\left(R^{2}\right.$, ranged from 0.9869 to 0.9931 ).

\section{Chemicals, reagents, and materials}

All reagents and solvents were analytical and chromatographic grade, and were obtained from Sigma-Aldrich (St. Louis, MO, USA) and Merck (Hohenbrunn, Germany). FAMEs standard mixture (C12 - C22) was prepared from single standard purchased from Grace (USA) and Supelco Inc. (Bellefonte, PA, USA).

\section{Conclusions}

The two methods $\left(\mathrm{BF}_{3} / \mathrm{MeOH}\right.$ and $\left.\mathrm{HCl} / \mathrm{MeOH}\right)$ for fatty acids analysis of forage with complex matrix and low lipid content from grassland, based on direct transmethylation, without prior extraction, give the same qualitative and quantitative results. Both methods produced considerable amount of interfering compounds, but smaller in $\mathrm{BF}_{3} / \mathrm{MeOH}$ method case. The protection of injector and column against the contamination is better when the quantities of interfering compounds in the final hexane extract are smaller. Also the statistical parameters of $\mathrm{BF}_{3} / \mathrm{MeOH}$ method are superior to $\mathrm{HCl}$ / $\mathrm{MeOH}$ method. This simple, non-expensive and fast method, using small amounts of samples and small amounts of environmentally unfriendly reagents $\left(\mathrm{BF}_{3} /\right.$ methanol as derivatization reagent and hexane as FAMEs extractor reagent) was applied with good accuracy and sensitivity for the determination of free or combined fatty acids (C12-C22, saturated and unsaturated) in complex forage matrix from grassland. Future studies are needed to elucidate whether the method requires the introduction of an additional SPE clean-up step, like in $\mathrm{HCl} / \mathrm{MeOH}$ method case.

\section{Additional material}

Additional file 1: Supplementary figure. Figure of vial colours.

\section{Acknowledgements}

I am grateful to the Romanian Ministry of Education, Research and Innovation, and CNCSIS (Romania) for the financial support, Postdoctoral Programme PD_576 Nr. 207/August 2010 and to my colleague PhD Prof. losif Gergen for helpful advices and technical assistance. The analyses of forage's fatty acids contents were made in "Sustainable Agriculture and Food Safety Laboratory" of Banat's University of Agricultural Sciences and Veterinary Medicine from Timisoara, RO 300645, Romania.

\section{Authors' contributions}

$\mathrm{MH}$ study paper design develops the forage sampling and the comparative researches, analyses and performs the statistical interpretation of results. 


\section{Competing interests}

The author declares that they have no competing interests.

Received: 28 October 2011 Accepted: 23 January 2012

Published: 23 January 2012

\section{References}

1. Moffatt RJ, Stamford B: Lipid Metabolism and Health CRC Press: New York, NY, USA; 2005

2. Chilliard Y, Ferlay A, Mansbridge RM, Doreau M: Ruminant milk fat plasticity: nutritional control of saturated, polyunsaturated, trans and conjugated fatty acids. Ann Zootech 2000, 49:181-205.

3. Raes K, De Smet S, Demeyer D: Effect of dietary fatty acids on incorporation of long chain polyunsaturated fatty acids and conjugated linoleic acid in lamb, beef and pork meat: a review. Animal Feed Science and Technology 2004, 113:199-221.

4. Grashorn MA: Functionality of Poultry Meat. J Appl Poult Res 2007, 16:99-106

5. Ponte PIP, Prates JAM, Crespo JP, Crespo DG, Mourao JL, Alves SP, Bessa RJB, Chaveiro-Soares MA, Ferreira LMA, Fontes CMGA: Improving the Lipid Nutritive Value of Poultry Meat Through the Incorporation of a Dehydrated Leguminous-Based Forage in the Diet for Broiler Chicks. Poult Sci 2008, 87:1587-1594.

6. Shin D, Narciso-Gaytan C, Park JH, Smith SB, Sanchez-Plata MX, RuizFeria CA: Dietary combination effects of conjugated linoleic acid and flaxseed or fish oil on the concentration of linoleic and arachidonic acid in poultry meat. Poult Sci 2011, 90:1340-1347.

7. Scollan N, Hocquette JF, Nuernberg K, Dannenberger D, Richardson I, Moloney A: Innovations in beef production systems that enhance the nutritional and health value of beef lipids and their relationship with meat quality. Meat Science 2006, 74:17-33.

8. Dewhurst RJ, Shingfield KJ, Lee MRF, Scollan ND: Increasing the concentrations of beneficial polyunsaturated fatty acids in milk produced by dairy cows in high-forage systems. Anim Feed Sci Technol 2006, 131:168-206

9. Lepage G, Roy CC: Improved recovery of a fatty acid through direct transesterification without prior extraction or purification. J Lipid Res 1984, 25:1391-1396.

10. Lepage G, Roy CC: Direct transesterification of all classes of lipids in a one-step reaction. J Lipid Res 1986, 27:114-120.

11. Marangoni F, Colombo C, Galli C: A method for the direct evaluation of the fatty acid status in a drop of blood from a fingertip in humans: applicability to nutritional and epidemiological studies. Anal Biochem 2004, 326:267-272

12. Kaveri SB, Nadaf HL, Salimath PM: Comparison of two methods for fatty acid analysis in peanut (Arachis hypogaea L.). Indian J Agric Res 2009, 43:215-218.

13. Alves SP, Cabrita ARJ, Fonseca AJM, Bessa RJB: Improved method for fatty acid analysis in herbage based on direct transesterification followed by solid-phase extraction. J Chromat A 2008, 1209:212-219.

14. Andreishcheva EN, Isakova EP, Sidorov NN, Abramova NB, Ushakova NA, Shaposhnikov GL, Soares MIM, Zvyagilskaya RA: Adaptation to Salt Stress in a Salt-Tolerant Strain of the Yeast Yarrowia lipolytica. Biochemistry (Moscow) 1999, 64:1061-1067.

15. VanStappen G, Sui L, Xin N, Sorgeloos P: Characterisation of high-altitude Artemia populations from the Qinghai- Tibet Plateau, PR China. Hydrobiologia 2003, 500:179-192.

16. Weston TR, Derner JD, Murrieta CM, Rule DC, Hess BW: Comparison of catalysts for direct transesterification of fatty acids in freeze-dried forage samples. Crop Science 2008, 48:1636-1641.

17. Alves SP, Cabrita ARJ, Fonseca AJM, Bessa RJB: Effect of a Purification Step and the Type of Internal Standard Used on Fatty Acid Determination of Grass and Maize Silages. J Agric Food Chem 2009, 57:10793-10797.

18. Wyss U, Collomb M: Fatty acid composition of different grassland species. 23rd EGF General Meeting on "Grassland in a Changing World" Grassland Science in Europe 2010, 15:631-633.

19. Rontani JF, Cuny, Grossi V: Photodegradation of chlorophyll phytyl chain in senescent leaves of higher plants. Phytochemistry 1996, 42:347-351.

20. Eller FJ: Interference by methyl levulinate in determination of total fat in low-fat, high-sugar products by gas chromatographic fatty and methyl ester (GC-FAME) analysis. J Assoc Off Anal Chem Int 1999, 82:766-769.
21. Palmquist $\mathrm{DL}$, Jenkins $\mathrm{TC}$ : Challenges with fats and fatty acid methods. J Anim Sci 2003, 81:3250-3254.

doi:10.1186/1752-153X-6-8

Cite this article as: Harmanescu: Comparative researches on two direct transmethylation without prior extraction methods for fatty acids analysis in vegetal matrix with low fat content. Chemistry Central Journal 2012 6:8.

\section{Publish with ChemistryCentral and every scientist can read your work free of charge \\ "Open access provides opportunities to our colleagues in other parts of the globe, by allowing anyone to view the content free of charge." \\ W. Jeffery Hurst, The Hershey Company.}

- available free of charge to the entire scientific community

- peer reviewed and published immediately upon acceptance

- cited in PubMed and archived on PubMed Central

- yours - you keep the copyright

Submit your manuscript here:

http://www.chemistrycentral.com/manuscript/<smiles>c1ccccc1</smiles>

ChemistryCentral 